\title{
Physical Properties of the Zinc Oxide-Eugenol Impression Pastes
}

\author{
G. E. MYERS and F. A. PEYTON \\ University of Michigan, School of Dentistry, Ann Arbor, Michigan
}

The zinc oxide-eugenol impression pastes have been available to the profession since the 1930's and have become increasingly popular in impression procedures in denture prosthesis. Before this time, mixtures of zinc oxide and eugenol were used as dental cements, being mentioned for this purpose in the literature as early as $1887,{ }^{1}$ and such mixtures are still widely used as temporary dental cements. Investigations of the properties of zinc oxide-eugenol mixtures have been directed to an evaluation of either the dental cements or the impression pastes. The basic properties of these cements and impression pastes are, to a large extent, reciprocal. Early investigations $^{2-7}$ were largely concerned with desirable compositions of mixtures for impression pastes or dental cements. Later studies ${ }^{8-10}$ of the fundamental nature of the reaction between zinc oxide and eugenol have revealed the nature of the setting reaction, and more recently, the clinical and physical properties of commercially available impression pastes have been investigated. ${ }^{11-14}$

A large number of zinc oxide-eugenol pastes are available, which are essentially similar in general properties but differ in their clinical behavior. Variations are noted from one product to another chiefly in relation to setting times, consistency of the mixed material, and the physical qualities of the set impressions, including hardness, brittleness, tackiness, and ease of separation from the case. Products vary also in their reaction to environmental changes and the effects which temperature and humidity have on the setting qualities of the paste. Variations may exist in the effect of storage on the physical and clinical properties of these products. The data here presented represent part of a study of clinical and physical properties of the zinc oxide-eugenol impression materials, which was undertaken in order to compare and evaluate the more commonly used products available to the dentist.

\section{MATERIAIS AND METHODS}

The fifteen products discussed in this paper were purchased on the open market and are listed alphabetically by their proprietary names in Table 1 . All tests were carried out on samples made from materials having the same batch number.

The manufacturer's directions regarding proportioning and mixing were followed for all products. Preliminary tests showed that those pastes supplied in a tube could

This report is compiled from data obtained in studies supported by contract No. DA-49-193-MD2001, between the Office of the Surgeon General, Department of the Army, and the University of Michigan.

Received for publication January 28, 1960; revised by authors July $27,1960$. 
be dispensed by length with sufficient accuracy to give reproducible results if care was exercised. Measured lengths of base and accelerator, which varied with the different test procedures according to the size of sample required, were dispensed onto the pad directly from the tube and the mixing timed accurately.

The progress of the hardening process which occurs as the zinc oxide-eugenol paste sets can be examined by means of a suitable penetrometer. In this study, the Krebs penetrometer with a cylindrical indenter $1.59 \pm 0.13 \mathrm{~mm}$. in diameter and with a total load of $50 \mathrm{gm}$. was used. The freshly mixed impression paste was placed in a metal ring 1 inch in diameter and $\frac{1}{8}$ inch deep, and the top surface of the paste was leveled off. The indenter was applied to the surface for 10 seconds at 30-second intervals, and the penetration noted on the dial gauge. An average of three sets of data at each

TABLE 1

Products Tested

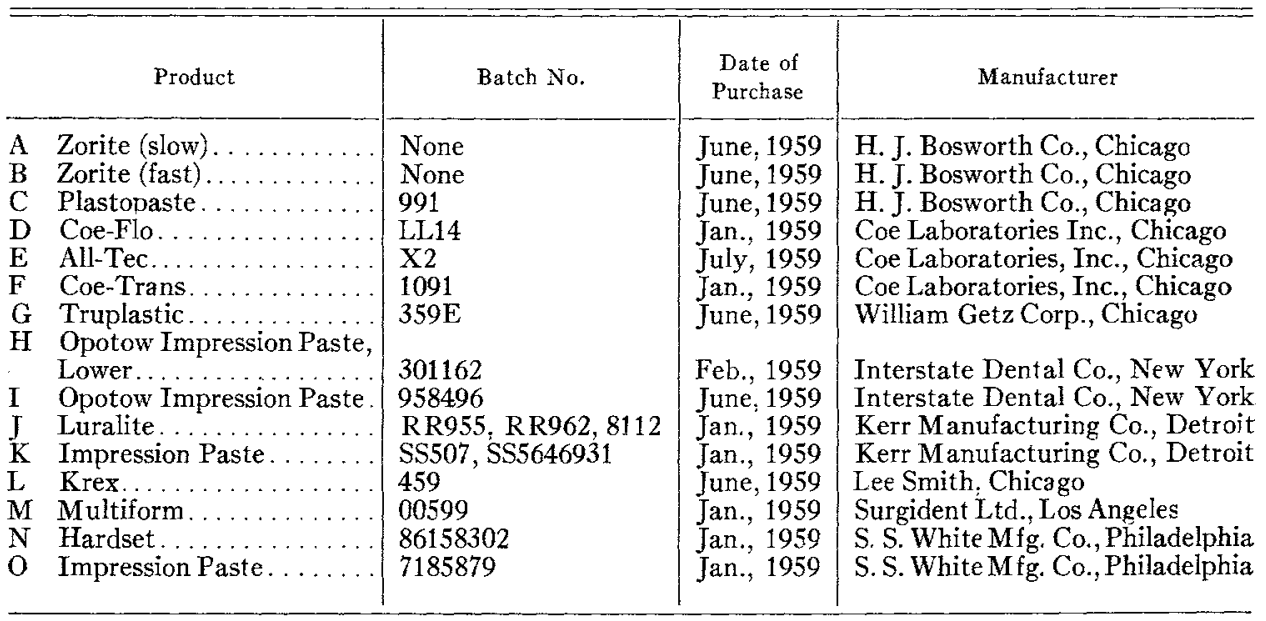

time interval was taken and the penetration plotted against time to give a curve. During the period when the paste is fluid, the indenter penetrates the specimen completely. As hardening occurs, however, the extent of penetration decreases rapidly until a constant minimum penetration is obtained. The value of the constant minimum reading will vary according to the hardness of the set impression.

For the routine determination of initial and final set time, simpler methods involving less expensive apparatus than the Krebs penetrometer can be used. If a suitably shaped instrument such as a short piece of steel rod of about the diameter of a dental bur shaft is applied to the surface of a freshly mixed zinc oxide-eugenol paste and then removed, the paste will adhere to the rod and string out as it is withdrawn. Repetition of this procedure at definite time intervals will reveal a point at which the paste no longer develops strings when the rod is withdrawn. This change in property occurs at the time of initial set and the loss of the normal working qualities of the paste. In the tests conducted in this study, a steel rod $2.4 \mathrm{~mm}$. in diameter with a flat end and rounded edges and weighing $10 \mathrm{gm}$. was applied to the surface of the paste at 20 -second intervals. The end of the rod was wiped clean after each 
application. Initial set time was recorded as the time at which stringing no longer occurred and was recorded to the nearest half-minute. The average for three determinations was taken. Final set was determined with a 1/12-inch Gillmore needle weighing $\frac{1}{4} \mathrm{lb}$. Freshly mixed paste was loaded in a ring 1 inch in diameter and $\frac{1}{8}$ inch deep, and the surface of the paste leveled off. The needle was applied to the surface for 10 seconds at 30-second intervals. At first, the needle penetrated the specimen completely, but, as the paste hardened, the penetration decreased in depth until a series of impressions of approximately equal depth was obtained. The time of the first of such a series of similar indentations was recorded as the final set time.

To compare the initial set times obtained in the rod test described above with the clinical manipulation of these materials, two series of tests were run on the same mixes of eleven zinc oxide pastes. The mix of paste was made according to the manufacturer's directions and divided into two equal parts. One part was used to determine the initial set, using the rod method described above. The initial set of the other part was determined by assessment of the point at which the paste would no longer be used to record an impression. The two sets of times were recorded separately by independent observers and subsequently compared when all eleven materials had been investigated.

The consistency of the zinc oxide paste was determined with the modified slump test, which has been used by other investigators. ${ }^{11,}{ }^{12}$ A measured quantity of mixed paste is placed between two glass plates, and a weight applied for a fixed time. The diameter of the resulting disk of impression material is used as a measure of the consistency of the impression paste. The more fluid the consistency, the larger the disk diameter. In this study, $0.5 \mathrm{ml}$. of freshly mixed impression paste was placed on a glass plate; $1 \frac{1}{2}$ minutes after the beginning of the mix another glass plate weighing $20 \mathrm{gm}$. was placed on the paste, immediately followed by a 500 -gm. weight. Ten minutes after the start of the mix the weight was removed, and the average diameter of the disk was determined to the nearest millimeter by measuring the maximum and minimum diameters. At least three determinations were completed for each product, and the average value recorded. To compare these consistency values with the clinical behavior of the impression pastes, measured quantities of the paste were mixed, and the consistency assessed by watching the flow of the mixed material from the mixing spatula. Three categories can be readily recognized: (a) the paste does not flow from the spatula, (b) the paste flows slowly from the spatula, and $(c)$ the paste flows freely from the spatula.

The hardness of the set impression was measured in this study by the degree of penetration of the penetrometer needle applied to a specimen at $\frac{1}{2}$ hour after the beginning of the mix. A Krebs penetrometer was used with an ASTM D-5 needle, and a total indenter load of $100 \mathrm{gm}$. The specimen mix was flowed into a metal ring 1 inch in diameter and $\frac{1}{8}$ inch in depth. Thirty minutes after the beginning of the mix, the needle was applied to the surface of the specimen and allowed to penetrate for 10 seconds. The extent of penetration was measured to the nearest $0.1 \mathrm{~mm}$. Three such determinations were completed for each of the seven products examined, and the averages, adjusted to the nearest $0.1 \mathrm{~mm}$., were recorded.

Further to examine the properties of the set impression paste, a flow test was per- 
formed on cylindrical samples made from standard mixes of eight products. A sample made by filling a mold $10.0 \mathrm{~mm}$. (0.394 inch) in diameter and $6 \mathrm{~mm} .(0.236 \mathrm{inch})$ high was subjected to a load of $1 \mathrm{~kg}$. for 10 minutes, and the extent to which the sample shortened was measured. The percentage of shortening was then calculated and recorded as the percentage of flow.

The facility with which an impression can be removed from a cast was examined by filling a metal ring $16 \mathrm{~mm}$. in diameter and $6 \mathrm{~mm}$. high with freshly mixed paste and allowing it to set. The ring was boxed with a strip of wax. Five minutes after final set, a mix of dental stone was poured into the mold so formed. The mold was vibrated to remove air bubbles, and the stone was allowed to harden. Two hours later the mold was immersed in water at $140^{\circ} \mathrm{F}$. for 15 minutes, then the cast was removed from the ring of zinc oxide. At least three specimens were prepared for each product, and the surface of each specimen was examined under low-power magnification for the surface quality and the presence of any adherent impression material. The zinc oxide surface was also examined for any indication of adherent stone.

To examine separation of the cast from the impression material under conditions more closely resembling clinical conditions, where the presence of rugae and other surface irregularities of the mucous membrane exist, impressions were taken of a rubber model of an upper edentulous mouth. One impression was taken with each of the fourteen products, using an acrylic tray adapted to the model. The same technique of pouring stone and separating from the impression as described above was followed, and the casts obtained were examined under low-power magnification.

A silicone rubber test block was used to evaluate the ability of the zinc oxideeugenol products to register fine detail. The rubber test block, approximately $1 \frac{1}{4}$ inch square, was made by duplicating the surface of a metal block on which V-shaped grooves had been cut, having the following widths: $0.0015,0.0021,0.0030,0.0042$, $0.0060,0.084$, and 0.0120 inch. A metal ring 1 inch in diameter and $\frac{1}{8}$ inch high was placed over the rubber test block so as to include portions of all seven lines. The ring was overfilled with zinc oxide paste, and a small glass plate was placed over the ring. A 50-gm. weight was then applied, and the paste allowed to set. Two minutes after the final set, the impression was removed and examined under low-power magnification to check for the reproduction of all seven lines. The impression was then boxed with wax and poured in stone. One hour later the cast and impressions were immersed in water at $140^{\circ} \mathrm{F}$. for 15 minutes and then separated. The stone models were examined for reproduction of the impressions.

\section{RESULTS}

The setting characteristics of seven products were studied, using the Krebs penetrometer, and three typical curves are shown in Figure 1. Some products, for example, $F$, harden very rapidly, whereas, with other products, such as $B$, the hardening occurs over a longer period of time.

Values obtained by the rod method of testing initial set are given in Table 2, and range from 1.5 to 4.0 minutes, nine of the values being less than 3 minutes.

The final setting times of fifteen products when tested by the $\frac{1}{4} \mathrm{lb}$. Gillmore needle are listed in Table 3. These values range from 3.0 to 15.0 minutes. 


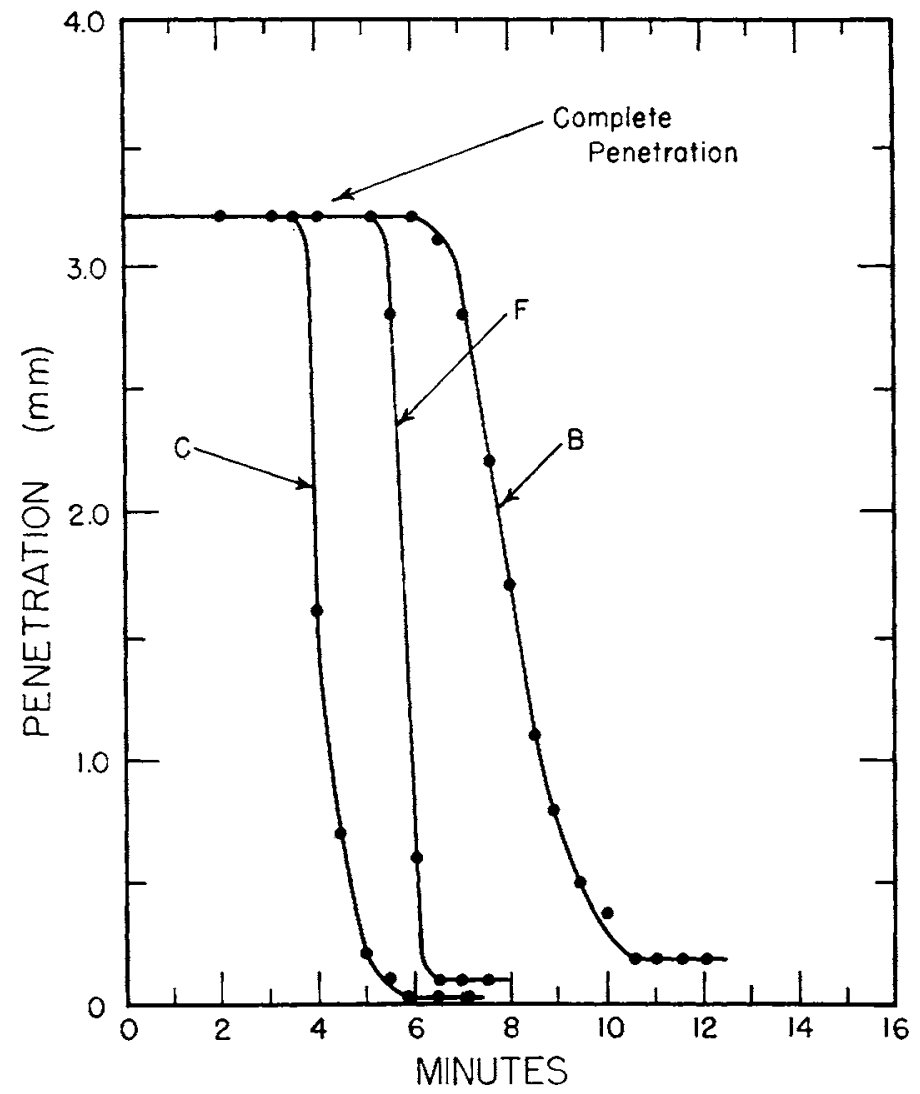

Fic. 1. - Setting characteristics of three zinc oxide pastes as determined by the Krebs penetrometer

TABLE 2

INITIAL SET TIMES DETERMINED BY ROD METHOD AND BY Clinical Evaluation

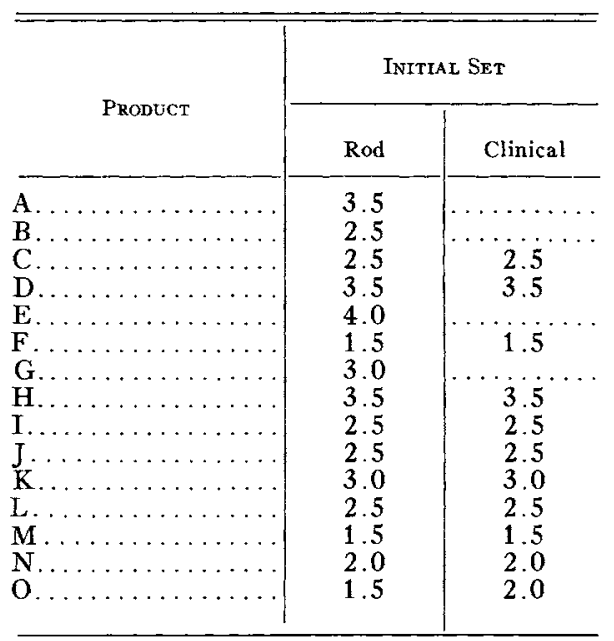


The results obtained in the comparison of initial set times as determined by the rod method with those assessed from the clinical behavior of the pastes are listed in Table 2. It can be seen that the values agree for ten of the eleven products.

The consistency values obtained for fifteen products using the modified slump test are shown in Table 4, along with the values recorded in the clinical evaluation of consistency.

The results of the test for hardness of the set impression are listed in Table 5 and range from 0.5 to $3.2 \mathrm{~mm}$.

TABLE 3

Final Set Times Obtained with Krebs

PENETROMETER AND $\frac{1}{4}$-LB.

GILLMORE NEEDLE

\begin{tabular}{|c|c|c|}
\hline \multirow[b]{2}{*}{ Product } & \multicolumn{2}{|c|}{ Final Set (Mindtes) } \\
\hline & $\begin{array}{c}\text { Gillmore } \\
\text { Temp. } 70^{\circ} \mathrm{F} \text {. } \\
\text { R.H. } 59 \text { Per } \\
\text { Cent }\end{array}$ & $\begin{array}{c}\text { Krebs } \\
\text { Temp. } \\
75-77^{\circ} \mathrm{F} . \\
\text { R.H. } 46-49 \\
\text { Per Cent }\end{array}$ \\
\hline 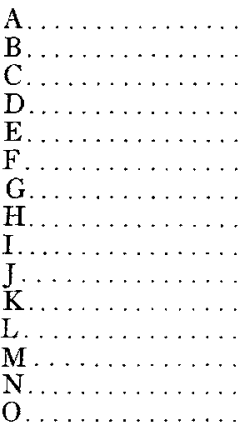 & $\begin{array}{r}4.0 \\
3.0 \\
4.0 \\
7.0 \\
7.0 \\
15.0 \\
3.5 \\
5.0 \\
6.5 \\
5.5 \\
5.0 \\
4.5 \\
3.5 \\
5.5 \\
11.5\end{array}$ & 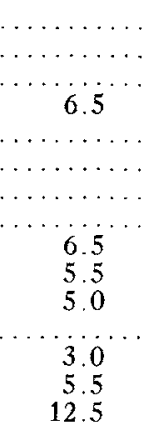 \\
\hline
\end{tabular}

The percentage flow of a cylindrical specimen was determined for eight products. The samples were tested at three time intervals after the final set, namely, 5 minutes, 1 hour, and 24 hours. The values obtained are shown in Table 6.

The fourteen products examined for the separation of the impression from the cast were all satisfactory in this respect. With eight of the products, a slight deposit was noticed on the stone when examined carefully under low-power magnification. However, in no case was the deposit of a nature or extent that would be significant in the practical use of these impression materials. In the test series in which impressions were taken of a rubber model of an edentulous maxilla, these results were confirmed, and no product presented any practical problems in respect to separation from the stone cast or quality of the cast surface.

All fourteen products tested registered the finest lines satisfactorily, and all the lines were reproduced in the stone casts. In three instances the impression failed to register the finest line on the first attempt. On repeating the test, however, with 
TABLE 4

Comparison of CONSISTENCY TEST VALUes With Clinical Flow

(Products Arranged in Order of Their Disk Size)

\begin{tabular}{|c|c|c|c|}
\hline Product & $\begin{array}{c}\text { Disk } \\
\text { Diameter } \\
\text { (Mm.) }\end{array}$ & $\begin{array}{l}\text { Clinical } \\
\text { Flow }\end{array}$ & $\begin{array}{c}\text { Initial Set } \\
\text { (Minutes) }\end{array}$ \\
\hline 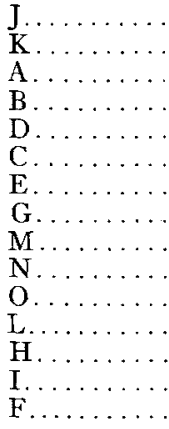 & $\begin{array}{l}50 \\
49 \\
49 \\
45 \\
44 \\
43 \\
43 \\
41 \\
40 \\
37 \\
37 \\
34 \\
34 \\
32 \\
27\end{array}$ & $\begin{array}{l}\text { Freely } \\
\text { Freely } \\
\text { Freely } \\
\text { Freely } \\
\text { Freely } \\
\text { Freely } \\
\text { Freely } \\
\text { Freely } \\
\text { Freely } \\
\text { Slowly } \\
\text { No flow } \\
\text { No flow } \\
\text { No flow } \\
\text { No flow } \\
\text { No flow }\end{array}$ & $\begin{array}{l}4.0 \\
5.0 \\
5.0 \\
2.5 \\
4.5 \\
4.0 \\
4.0 \\
3.0 \\
2.0 \\
3.0 \\
4.5 \\
3.0 \\
3.0 \\
2.5 \\
1.5\end{array}$ \\
\hline
\end{tabular}

TABLE 5

PENETRATION HARDNESS OF SET IMPRESSION PASTE, KREBS PENETROMETER, 30 MINUTES AFTER MIXING

\begin{tabular}{|c|c|c|}
\hline Product & $\begin{array}{c}\text { Penetration } \\
\text { (Mm.) }\end{array}$ & Type \\
\hline 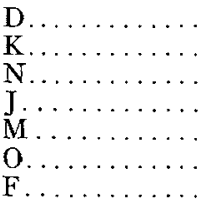 & $\begin{array}{l}0.5 \\
0.5 \\
0.6 \\
1.0 \\
1.5 \\
1.9 \\
3.2\end{array}$ & $\begin{array}{l}\text { Hard-set } \\
\text { Hard-set } \\
\text { Hard-set } \\
\text { Hard-set } \\
\text { Soft-set } \\
\text { Soft-set } \\
\text { Soft-set }\end{array}$ \\
\hline
\end{tabular}

TABLE 6

Percentage Flow Values of Seven Zinc OxideEugenol ImPRession PASTES AT ThreE Time INTERVALS AFTER FinaL SET

\begin{tabular}{|c|c|c|c|}
\hline \multirow{2}{*}{ PRODUCT } & \multicolumn{3}{|c|}{ PERCENTAGe FLoW at } \\
\hline & 5 Minutes & 1 Hour & 24 Hours \\
\hline $\begin{array}{l}\mathrm{D} \ldots \ldots \\
\mathrm{K} \ldots \ldots \\
\mathrm{N} \ldots \\
\mathrm{J} \ldots \ldots \\
\mathbf{\mathrm { M }} \ldots \ldots \\
\mathbf{O} \ldots \ldots \\
\mathbf{F} \ldots \ldots\end{array}$ & $\begin{array}{r}4.0 \\
5.1 \\
5.5 \\
6.8 \\
8.8 \\
13.7 \\
47.3\end{array}$ & $\begin{array}{c}0.83 \\
1.8 \\
2.4 \\
4.7 \\
4.0 \\
5.4 \\
26.3\end{array}$ & $\begin{array}{l}0.60 \\
2.0 \\
1.2 \\
2.8 \\
2.2 \\
2.4 \\
14.1\end{array}$ \\
\hline
\end{tabular}


special attention given to overfilling the ring and applying the weight, a satisfactory impression was obtained.

\section{DISCUSSION}

Setting times.-Of interest to the clinician is the time available in which to $\mathrm{mix}$ the paste, load a tray, and register an impression before the desirable flow qualities of the paste end with the occurrence of initial set. Such a period of time is customarily described as the manipulation or working time. Once the impression has been registered, a fairly rapid and well-defined hardening of the paste is desirable, and this quality is determined in the measurement of final set. From the slopes of the curves seen in Figure 1, it can be noted that the products differ in the rate at which hardening occurs. Some products, for example, $F$, harden rapidly, whereas with other products, such as $B$, the hardening occurs over a longer period of time. The working time or manipulation time of these pastes can be obtained by recording the time at which the indenter no longer completely penetrates the specimen. The final set can be obtained by noting the time at which the first of three constant minimum indentations is obtained. Another method of selecting the final set point from the penetrometer data is to establish an arbitrary penetration value for final set, for example, $0.2 \mathrm{~mm}$., and consider final set to have occurred when the penetrometer reading is less than that amount. A comparison of the final setting time obtained by the Krebs penetrometer with those obtained by the $\frac{1}{4}-1 \mathrm{~b}$. Gillmore needle is shown in Table 3 . For the seven products compared, the values are the average of three determinations expressed to the nearest half-minute. These determinations by two test procedures were not done on the same mix or at the same time, although conditions of proportioning, mixing time, temperature, and humidity were similar. Although the two sets of values do not match exactly, there is a sufficient correlation for the purpose to which these values are applied. For general testing purposes, it seems that either the Krebs penetrometer or the Gillmore needle can be used satisfactorily to determine the final set of these pastes and that the values from the two methods will correlate reasonably well.

Consistency.-In comparing the clinical quality of flow from the spatula and the values obtained from the modified slump test, the following facts are of interest. Those products which in the slump test had a value greater than $37 \mathrm{~mm}$. flowed freely from the spatula, and those products with a value of less than $37 \mathrm{~mm}$. did not flow from the spatula. Two products had a value of $37 \mathrm{~mm}$. in the slump test but exhibited different qualities of flow from the spatula, one flowing slowly from the spatula and the other not at all. This difference in flow qualities between two products with the same value on the slump test is thought to be due to the difference in initial set times of the two products. The initial set times are listed in Table 4, and it can be seen that the product which is more fluid in the clinical evaluation and flows slowly has a shorter initial set time than the product which clinically exhibits no flow. The influence of this difference in initial set times is responsible for two products, with clinically different consistencies, having the same disk size in the modified slump test, because the shorter initial set time reduces the period during which the 500 -gm. weight can act effectively on the specimen. This same factor may be influencing the disk sizes obtained with other 
products in the series, and the comparative clinical behavior of two products can be predicted only from their disk sizes when the setting times are approximately the same.

Quality of the set impression.-Certain qualities are necessary in the set zinc oxide paste if an impression is to fulfil its purpose in restorative dentistry. Qualities of special interest are the hardness, freedom from friability, freedom from tackiness, dimensional stability, compatibility with materials used to make a cast, and ease of separation from the cast. A satisfactory impression should be hard and firm enough not to bend or distort on removal from the mouth. It should not be brittle or friable in the set state, so that, if necessary, the impression can be returned to the mouth, and also to facilitate the subsequent pouring of the cast. In considering these properties it should be remembered, however, that the material is always well supported by a suitably designed impression tray. Some slight tackiness in the set impression is found in many products. Provided that this is not present to a degree that the impression will not separate easily from the cast, no clinical difficulties arise from this quality. The zinc oxide pastes have been shown ${ }^{9}$ to be sufficiently stable dimensionally for the purpose for which they are employed.

The values for the hardness of the set impression range from 0.5 to $3.2 \mathrm{~mm}$. In relation to the hardness of the set impression, many of the products fall into one of two categories. In one group, often referred to as the "soft-set products," the paste is comparatively soft when set and tends to bend rather than fracture when placed under stress. In the other group, referred to as the "hard-set products," the paste is hard and comparatively brittle in the set state, and when stress is applied to a free specimen, it will fracture. These qualities are related to the composition of the paste and are usually accompanied by other properties characteristic of each group. For example, the softset products are, in general, buttery in the freshly mixed state and do not flow readily. They usually set slowly, and the point of initial set is not well defined. On the other hand, the hard-set products usually are free flowing and set rapidly with a well-defined point of initial set. All products, however, do not fall clearly into one or the other of the above groups. Of the seven products tested, the four hard-set materials have values of $1.0 \mathrm{~mm}$. or less, and the 3 soft-set products have values of $1.5 \mathrm{~mm}$. or greater.

If the products are arranged in the order of their flow values as determined 5 minutes after final set, the sequence is the same as that seen when they are arranged in the order of their penetration hardness values. The hard-set products have flow values of less than 7 per cent, and the soft-set products have values of greater than 8 per cent.

\section{SUMMARY}

Several physical and clinical properties of the commercially available zinc oxide impression pastes were studied. An attempt was made to correlate the values obtained from bench tests for initial set and consistency with the clinical behavior of the pastes in regard to these properties. Correlation of the values obtained in the final set test using the Krebs penetrometer and the Gillmore needle was examined. The qualities of the set impression were investigated in relation to hardness, flow properties, separation from the cast, and detail reproduction. Initial set times of the fifteen products tested varied from 1.5 to 4.0 minutes. Nine of the fifteen products had an initial set value of less than 3 minutes. The final set times of the fifteen products determined with the 
Gillmore needle ranged from 3.0 to 15.0 minutes. Comparison of the values obtained in the rod test for initial set with the clinical behavior of these pastes showed a close degree of correlation. The initial set times as determined represented the time available in which the paste has to be mixed, loaded into a tray, and the impression registered. A comparison of the final set times determined with the Krebs penetrometer and the Gillmore needle shows a correlation sufficiently close for the purpose to which the values are applied. The values obtained in the consistency test varied from 27 to 50 $\mathrm{mm}$. When these values were compared with the clinical behavior of the pastes, it was found that pastes with a disk size in the consistency test greater than $37 \mathrm{~mm}$. flowed freely from the spatula and that those with a disk size less than $37 \mathrm{~mm}$. did not flow from the spatula. Initial set time may influence the disk size obtained in the consistency test. A short initial set time may give a smaller disk size than the consistency merits, as compared with a product of similar consistency but having a longer setting time. For this reason, disk sizes in the consistency test cannot be used as a basis of comparing the relative consistency of two pastes unless they have similar initial set times. From the clinical point of view, the zinc oxide impression pastes can be divided into three groups according to the nature of the flow from the spatula: (a) flows freely, (b) flows slowly, and $(c)$ does not flow. As measured with the Krebs penetrometer, the hardness of the set impression paste in seven products varied from 0.5 to $3.2 \mathrm{~mm}$. Those products described as hard set had values of $1.0 \mathrm{~mm}$. or less, whereas those known as soft-set products had a value of $1.5 \mathrm{~mm}$. or more. The percentage flow of the set impression paste measured 5 minutes after final set for eight products ranged from 3.8 to 47.3 per cent. The hard-set products had values of 7 per cent or less, and the soft-set products had values of 8 per cent or greater. At the end of 1 hour the percentage flow values were considerably reduced, and after 24 hours a further hardening was noted. All fourteen products tested separated satisfactorily from the stone cast. All fourteen products reproduced the finest line on the test impression block satisfactorily, and when the impressions were poured in stone, the lines were all reproduced on the cast.

\section{REFERENCES}

1. Tomes, J., and Tomes, C. A System of Dental Surgery. London: Churchill, 1887.

2. Ross, R. A. Zinc Oxide Impression Pastes, J.A.D.A., 21:2029, 1934.

3. KELLY, E. B. United States Patent No. 2,077,48, April 21, 1937.

4. Wallace, D. A., and Hansen, H. L. Zinc Oxide-Eugenol Cements, J.A.D.A., 26:1536, 1939.

5. Paffendarger, G. C., and Caul, H. J. Dental Cements: Dental Centenary Celebration Proc., March, 1940, p. 232. Baltimore: Waverly Press, 1940.

6. Lawrence, G. O. Impression Pastes, Austral. D. J., 45:207.

7. Molnar, E. J., and Sxinner, E. W. A Study of Zinc Oxide-Rosin Cements, J.A.D.A., $29: 744,1942$.

8. Harvey, W., and Petch, N. J. Acceleration of the Setting of Zinc Oxide Cements, Brit. D. J., $\mathbf{8 0}: 1$ and $35,1946$.

9. Copeland, H. I., Brauer, G. M., Sweenex, W. T., and Forziatr, A. F. Setting Reaction of Zinc Oxide and Eugenol, J. Research Natl. Bur. Standards, $55: 133,1955$.

10. SM.rth, D. C. The Setting of Zinc Oxide-Eugenol Mixtures, Brit. D. J., 105:313, 1958.

11. Skinner, W. E., Cooper, E. N., and Ziehm, H. W. Some Physical Properties of Zinc Oxide Eugenol Impression Pastes, J.A.D.A., 41 :449, 1950.

12. Asgarzadem, K., and Peyton, F. A. Physical Properties of Corrective Impression Pastes, J. Pros. Den., 4:555, 1956.

13. Clark, R. J., and Prillips, R. W. Flow Studies of Certain Dental Impression Materials, J. Pros. Den., $7: 249,1957$.

14. VIEIRA, D. F. Factors Affecting the Setting of Zinc Oxide-Eugenol Impression Pastes, J. Pros. Den., 9:70, 1959 . 